\title{
From Wordlist to Comparative Lexicography: The Lexinotes ${ }^{1}$
}

Tony Naden, Ghana Institute of Linguistics, Literacy and Bible Translation, Walewale, N.R., Ghana

\begin{abstract}
This paper sketches the history of the study of the languages of West Africa, particularly of their lexical resources, offered as a typical example of similar developments elsewhere in the world. The collection of wordlists from the languages and their use to establish genetic relationships is considered, with some practical observations on the improvement of this methodology. The final section reports on an ongoing project for a comparative dictionary in northern Ghana, particularly the use of simple semantic network studies both within and across languages. An appendix presents one of the preliminary papers circulated in connection with this project.
\end{abstract}

Keywords: COLONIALISM, COMPARISON, DICTIONARY, EXPLORATION, GUR, HISTORY, LANGUAGES, LEXICOGRAPHY, LEXICOLOGY, LINGUISTICS, SEMANTICS, VOCABULARY, WEST AFRICA, WORDLIST

\begin{abstract}
Abstrait: De la liste-de-mots au lexique comparatif - les lexinotes. Cétte étude présente d'abord une esquisse de l'histoire de l'étude, surtout sur le plan du lexique, des langues de l'Afrique occidentale, comme échantillon type des tels développements dans les autres régions pareilles. La fonctionnalité de la collectionnement et comparaison des listes de mots est abordé, avec des conseils pratiques pour l'usage des listes. Enfin on offre deux aspects des recherches en Ghana du nord envers un dictionnaire comparative: une appendice présente une des études préliminaires du projet.
\end{abstract}

Mots Clef: AfRIQUE OCCIDENTALE, COLONLALISME, COMPARATISME, DICTIONNAIRE, EXPLORATION, HISTOIRE, LANGAGES, LEXICOGRAPHIE, LEXICOLOGIE, LINGUISTIQUE, LISTE-DE-MOTS, SEMANTIQUE, VOCABULAIRE, VOLTAIQUE

\section{Introduction}

While several major civilizations in the history of the world have developed written traditions and some form of lexicography, it is post-Renaissance Western - or as one might have said a decade or so ago 'modern' - culture which has shown interest in the languages and lexicon of groups which are in some sense alien to it and accounted minor either in importance or number of speakers. The Greeks' attitude to the 'bleating' of foreigners ${ }^{2}$ was largely echoed in the attitude to non-Chinese or non-Arabic tongues by these respective civilizations?. 
Be that as it may, in spite of the inadequacies of lexicographical resources for contemporary African (for instance) societies - as regretted in Busane, 1990 , amongst other commentators - there is available in the world a considerable amount of published and archived material on the vocabulary of languages of smaller populations and those spoken in politically non-prominent areas. I want to develop here a sketch of the history lying behind these lexicographic resources, exemplifying - in a necessarily simplified, not to say simplistic, sketch - from the area with which I am most familiar, West Africa. For practical purposes the history of this region is typical of many parts of the world which were controlled or dominated by European powers in the colonial period, and now mostly constitute the 'third' or 'developing' world of 'the South'. From this base 1 then consider some ways forward to a more sophisticated understanding of: lexical systems, both within and across language boundariès.

\section{History: Early Fragments}

In most cases, the earliest information we have on the languages of West Africa and similar regions is in the form of unsystematic notes from early European explorers, traders or missionaries. Journals and travel tales of such persons may sometimes attempt to add local colour by quoting a phrase which the natives' "shouted", or "kept repeating", or whatever, at the particular point in the proceedings. These are usually explained as being their 'word" for "Welcome" or some other formulaic utterance - with no guarantee, of course, that we are being given what linguistic analysis would consider a word, rather than a phrase or a sentence. As Christian missionary work necessitates some kind of communication of more complex ideas, and Christians have in general been oriented towards written texts of Scripture, liturgy, and doctrinal definition, the Church sources may have more extended texts of such materials translated into local languages;

For this region a number of studies have been made of this early material by P.E.H. Hair (e.g. 1965, 1966, 1968). There are considerable problems because of the generally low view which the European recorders held of the African peoples and languages which they recorded, and both transcriptions and identifications are of ten difficult to interpret and relate to present-day languages and peoples. The whole question of the interaction of linguistic history and the history of peoples and migrations is still hazy, as explored in Naden (1988) for one region of West Africa. There is still plenty of untapped material in these early sources, particularly in archives of commercial and governmental sponsors of exploration/colonization in Europe. 


\section{History: Colonial Collections}

There followed a phase of more settled and organised penetration of West Africa by Europeans - what may be roughly described as the Colonial period. The exact political situation, and the effectiveness and manner of operation of colonial régimes, protectorates, and so on, were of course, multifarious in their realisations. A particular point to note for the West Coast is that the endemic diseases which made it 'The White Man's Grave' precluded settlement by outsiders such as was found in parts of East and Southern Africa, South Asia and so on. Traders, administrators and missionaries were basically expatriates, visiting for longer or shorter tours of duty, and the long-term involvement in the area of individuals was of ten curtailed by ill-health or death.

In this period, roughly from just before the middle of the nineteenth century to just after the middle of the twentieth, there was also the development in the Western academic world of ethnographic and linguistic studies alongside the existing fields of classical literature, history and philology. This is often seen as largely a result of the colonial experience in the broadest sense - including the expansion of the United States at the expense of Native America, with similar movements in Canada, and of Russia into northern Asia. The development of phonetics, and later of phonemic and structural syntactic analyses, moved forward under a considerable impetus from those attempting to give an account of the languages of Africa, the Americas, South and Southeast Asia, the Caucasus and Siberia. And conversely scholars looked to these areas for field studies of languages and cultures on which they could wield and refine their new analytical tools (some relevant thoughts are found in Goldsmith 1992), particularly the comment:

"it can hardly escape even the casual observer of the current phonological scene that it stands in profound debt to work on African languages" (149)

West Africa presented some particular restrictions in this period. There was a lack of large centralized states in much of the hinterland, and unsettled conditions consequent upon the break-up of earlier states which was partly the result and partly the cause, or at least the opportunity, of the growth of influence/interference by the European powers. The power and then the decline of slave-raiding; mostly done by local agents for trade to both coastal European and Saharan Arab/Tuareg/Berber traders, added to confusion and lawlessness - summed up in the folk-history of northern Ghana as "the days of Samori and Babatu" - two famed and feared land pirates who raided and plundered with private armies around the turn of the century (Naden 1988). These conditions, along with the 'White Man's Grave' effect, made it difficult to even determine the names and locations of peoples and languages. 
Symptomatic of this situation is the fact that the most important of the early collections, Koelle's 'Polyglotta' (1854), represents data gathered without visiting the areas where the languages were spoken at all. Koelle's informants were slaves freed by the British from traders and settled in Freetown, Sierra Leone. In some cases they had not spoken their mother tongues for many years, and information on the location where the language was spoken is in the form of memories of how many days' journey the slave caravan took to reach various landmarks between the informant's place of capture and the sea-port. Furthermore, the name of the language is often buried behind many layers of foreigners' pronunciations, epithets and designations in a variety of trade languages. In the face of these problems Koelle's data seem to be remarkably good, and his work is another major quarry for information on earlier states of the languages of the area (e.g. Köhler 1964, Prost 1966, Delord 1968).

The spirit of this period placed a value on the number of languages from which samples were collected (e.g. Christaller 1889, Delafosse 1904, Groh 1911, titles). I always mentally associate this with the collections of butterflies assembled by contemporary entomologists, or lovingly-assembled patterns of diatoms on slides prepared by microscopists. However, the factors which are mentioned above as deterring European settlement would also have had an effect: when a scholar was able to assemble the funding, personnel and equipment to mount an expedition to these areas which were so difficult to access, he wanted to come 'out' with as much material as possible, for who knew when the area could be studied again? Because of the uncertainty over names and locations it is necessary to consult records of explorers, such as Binger (1892), as well as those explicitly studying language and culture.

The major aim of this activity was the establishment of genetic relationships by comparison of languages. The great success story of Indo-European comparative-historical work in the nineteenth century was both an inspiration and a challenge to those working in other parts of the world. A further reason for the collection of a large number of language samples was the establishment of an adequate data base for comparison. However it is noteworthy that the initial advances in this approach for Africa came in Bantu studies in the eastern and southern areas of the continent (all through the nineteenth century, but note particularly Meinhof 1906), partly because of the substantial group of obviously-related Bantu languages, but surely also because in the areas where there were European settlers there was the opportunity to study some major languages in greater depth. These results then fed into our area with studies like Westermann (1935).

\section{History: Consolidation}

The period roughly from the end of the first World War to the time of the independence of the West African nations from colonial rule formed a time of 
consolidation, though because of various economic and political problems results continue to be refined and published. It is true that 'new' languages may still be identified (e.g. Naden 1986a), and new collections of data appear, as in Dakubu $(1977,1980)$ or the work of the late, indefatigable, Fr. Prost (from a long list, especially important here is the series of articles on 'Atakora' languages culminating in the 1975 wordlists). However, improved accessibility, education of speakers of the languages, and the cumulative results of the earlier studies, have resulted in a fairly reliable picture of the names, locations and nature of most languages in the area. One concrete manifestation of this is the publication of maps and inventories for particular countries or areas (e.g. Brasseur and le Moal 1963, Hansford et al. 1976, and for our area Hall 1983).

Cumulative research results can be seen in areal summaries like Lavergne de Tressan (1953), leading into the Handbook of African Languages of Westermann and Bryan (1961), and the Africa-wide rethinking in Greenberg $(1966 / 70)$. A key development for the Gur languages, was the study of Swadesh et al. (1966). These findings are taken up by Bendor-Samuel (1971), summarized by Fivaz and Scott (1977) and revised by Bennett and Sterk (1977). Meanwhile, Manessy was publishing results of studies in Gur from the viewpoint of the francophone countries, notably (for our focus here) Manessy (1975, 1979); and Mukarovsky $(1977,1976)$ offered comparative material from his own research. A new synthesis is presented in Bendor-Samuel (1989), containing Naden (1989) for Gur.

At the same time studies of individual languages continue to be made. In our area there is still a shortage of full-scale reference or academic grammars, but pedagogic grammars are made for practical purposes (e.g. Riccitelli 1955, Wilson 1972). Similar practical studies are also made in the lexical domain (e.g. Durand 1953, Melançon and Prost 1972), and there are also dictionaries published for the development of literacy and practical use of the languages (Blass 1975, Langdon and Breeze s.a.) and as part of a research project (cf. Spratt and Spratt s.a., Arana and Swadesh 1967, Kröger 1992). Particularly noteworthy is the project at Saarbrücken University where African scholars are enabled to pursue masters' level studies while contributing to a series of dictionaries of their languages (cf. Lebizaka 1979, Badjona 1983, Derman 1983, Katia 1983).

\section{Wordlists: Techniques}

It has been a basic assumption above that much of the early sampling of languages was in the form of the collection of wordlists. In a brief visit to the area where a language is spoken, or within the limited time spent with an informant, perhaps even with no common language of communication, or working through an imperfectly-understood lingua franca or chain of interpreters, it is certainly easier to elicit names of common objects, or actions, than to get a a reliable record of morphological paradigms or syntactic structures. While there 
are numerous limitations and pitfalls in wordlist-collection, this can still be a useful tool among many in the toolbag of the student of these languages from the point of view of establishing names, distribution, usage and relationships.

This methodology was superseded by Swadesh (1950) with his lexicostatistic theory, which crucially bases comparative study on a specific wordlist (Swadesh 1953) of 200 items, claimed to be universally applicable as a core of basic vocabulary not only resistant to innovation but also undergoing change at a fixed rate. The glottochronology corollary claimed that this would make it possible to go beyond the grouping of languages by closeness of genetic relationship to establishing the length of real time elapsed since any pair of languages separated. We may seriously doubt the absolute percentages and centuries claimed by the proponents of the method, but it seems unnecessary to deny that within a given family or subfamily the relative distances are usefully mapped by this method. Some attempts have been made to refine the approach with further statistical analyses, as in Bennett and Sterk (1977), though the results have been queried (cf. Schadeberg 1986). My own reservation concerns not so much the method as the basic data on which it operates - a set of complete and accurate wordlists would probably yield better results under both the Swadesh and Benett/Sterk kind of analyses.

In practical terms the use of Swadesh lists has a few problems which can be minimised by careful use. The claim that the 'Swadesh-200' list is universal, has to be treated with caution. For example, it makes a wry point about everyone having lice (item $\# 22$ in the list 4 ), while not everyone has houses. In applying this list, one encounters the following typical problems of basic wordlists:

a) Unknown referent: in tropical Africa (with no high mountains) "ice", "snow" and "freeze" (\#148-150) are non-existent, and, therefore, not lexicalized.

b) Lexical distinction not made: "green" and "yellow" (\#88, 89) may not be lexicalized (low saturations are 'white' (\#90), high 'black' (\#91) and 'red" (\#87) respectively (cf. Berlin and Kay 1969 and the vast literature spawned thereby). "Wife" (\#146) may be "woman" (\#16), possessed.

c) Wordclass: the Englishs stimulus term belongs to a particular wordclass; merely glossing it with a target word of a different class is misleading Mampruli zibi-does not mean "dark" (\#152) but "be dark". There is also wordclass ambiguity e.g., "sleep" (\#60) and "fear" (\#191) can be a noun or a verb.

d) Ambiguous word: the stimulus item may be patently ambiguous "fly" may be an insect or the action of a bird, though at (\#64) the neigh- 
bouring verbs dictate the latter interpretation. But.is "burn" (\#84) "the fire is burning", "burn the grass!", "I burned my finger", or "I burned the dinner" ...?

e) More distinctions in target: in some cases we may feel that the stimulus is unambiguous in the English semantic system, but more fine-grained distinctions are made in the target language/culture. Is the "louse" (\#22) a fowl-louse, a dog-louse, or a human louse? To "wash" (\#123) may be different if the object is oneself, a baby, or clothes.

f) Grammatical frame: languages differ as to what form of the verb is best for citation: imperative, third person past, or first person singular. And the best form for exemplification may not be the best for elicitation. It may be useful to get several morphological 'principal parts' - in NigerCongo with its historical noun-class system it is very desirable to have singular and plural forms of all nominals. Prepositions ("with, in, at" $\# 139-141)$ are both fuzzy in reference and need a grammatical frame to show their usage. Other items needing grammatical context are "if" (\#142), pronouns (\#1, 2, 3, 102, 103), deictics (\#4, 5, 107, 108), interrogatives $(\# 6,7,104-106)$ and "not" (\#8).

In most cases the solution is to make clear the exact sense and grammatical class of the item given. The items needing context should be elicited in a set context:

1. I will not ${ }^{6}$ sleep. $\mathbf{N}$ ku gbisi.

...

60. I will not sleep. $\mathrm{N}$ ku gbisi.

...

140. The stone is in the pot. Kugri be la dukku ni.

I would always advise adding to the standard list rather than revising it and removing difficult items. The value of the standardized list is that it is standard. If any sample is available for a little-known language it is likely to be a Swadesh 'first 100 '. One can specify which sort of louse, either after collecting the term or in advance. Someone familiar with the sort of lexicalization patterns operative in a geographical or linguistic area can modify the list by specifying sense-discriminations, contextual frames, and additional locally-important vocabulary ("cow", "house", "Chief", "pot" and so on). The modified list can be used consistently by its compiler, at least, and if possible by colleagues, students, or as wide a circle of cooperating researchers as can be recruited. 


\section{Ways Forward: Thesaurus}

Items on wordlists like those of Swadesh, or the larger 550-word list of Greenberg, are usually subgrouped by meaning: body parts, verbs of posture, colour terms, and so on. This has been noted above as sometimes helping to disambiguate the English word (if "fly" was next to "louse" it would be the insect; between "swim" and "walk" it is the verb). This may also help informants in what is already a strange and arbitrary task, and is an improvement on presentation in alphabetical order which has sometimes been advocated, as long as one is working with a single wordlist. When published dictionaries, nonstandard wordlists, or several different standard lists are consulted, the virtues of alphabetical order for location become apparent - I had to spend some time compiling an alphabetical index of items in Swadesh and Greenberg lists, and data lists published by Mukarovsky (1977, 1976), Dakubu (1977, 1980) and Manessy (1975 and 1979). Computerized data processing cuts this knot, items can be grouped semantically so that the user can 'browse' among a set of related meanings, while a specific item can be located by the machine without the user being concerned with the search method used.

As part of the researches of GILLBT in languages of Ghana, we have developed an etic thesaurus of English stimulus-words grouped according to general West African cultural patterns, e.g., items sold in the same section of a market, tools and action verbs used in discussing cereal farming, and so on. A numerical code makes it possible to search for semantically-related items, while the hard-copy version has a full alphabetical index. Researchers are encouraged to use the etic list as a beginning, and then try to develop ways of reshaping the material in accordance with the emic judgements of speakers of each language. This is valuable for the study of individual languages, but it also feeds into the comparative enterprise, because one problem of wordlistbased comparison is semantic slippage - Language B may have a cognate of a given Language $\mathrm{A}$ word but the meaning has changed so that it will not be given in response to the same stimulus item. With semantic indices from the thesaurus system, a computer can locate possible cognates which have undergone this slippage, and inversely, examples of slippage across related languages are additional evidence for co-membership of an emic semantic class.

\section{Ways Forward: Comparative Dictionary}

From the comparative-historical viewpoint, the ultimate aim of this research is the production of a dictionary of the Westem Oti/Volta (W.O/V) languages. In one sense this is merely a superior version of the wordlist-comparisons like those of Swadesh et al. (1966), with a larger inventory of items, and based in many cases on ongoing research, even published dictionaries, in the individual languages. The sort of detailed sense-discriminations, usage notes, exemplifi- 
catory citations, and so on, offered by the dictionary of a single language, or even a bilingual dictionary for a pair of languages, cannot be usefully utilized for a group of some sixteen to twenty languages or named dialects. On the other hand, the thesaurus research does make it possible to group items in a more rigorous semantic network. The approach makes it possible to deal with a specific problem of wordlist work, the subcase of the target-language distinctions problem which is focussed on by Sankoff:

"In reality, although for some meanings it may be easy to find unique lexical representations, for others it may be difficult to choose between two, three or more words." (1970:565)

Take, for example, 'the word' given in W.O/V wordlists for "river". On the basis of the data available, one could distinguish three sub-groups of the languages, with "river" as something like "KUL-GA, "MOG-RI and *BUL-GA respectively. However, working at greater depth in one specific language I found that all three terms existed (in the same language group), kuliga (in Mampruli (MP)) being the place you go to for water - river, well or waterhole; mo'ari is a large body of water which does not dry up even in the dry season, and is, therefore, a big river, natural lake or artificial reservoir; and buliga is a well or spring where water seeps or springs or flows. Further research in to other languages of the group showed that most, if not all, have all three words with comparable, if not identical, distinctions.

As a result I set about presenting more detailed discussions of problematic semantic fields, with the data available to me so far laid out in wordlists for individual glosses, and circulating these "Lexinotes" to researchers working on, or interested in, these languages. Those who. received the notes were (or are, the series is still being issued intermittently) requested to return corrections or additions to the data and interpretations given. Thus one of some twenty-five topics proposed is "Water", including not only the three 'river' words above but also the word for "water" itself (which may, in fact, be a major shared-innovation defining the $W . O / V$ group) and also referents like "pothole, puddle", "swamp", the verb "to flow", and so on. Other areas discussed are colour terms, or words for "sun" and "God", which are obviously related although the present-day cultures show no sign of sunworship. As an example of these Lexinotes, I append the partially revised text of one of the earlier notes, on verbs of motion (cf. Appendix).

At present I envisagse a publishable comparative dictionary to contain entries like the individual wordlists ("ARRIVE", etc.) in the Lexinote arranged according to semantic fields in an overall thesaurus-style framework. Where there is a problem in specifying W.O/V discriminations with English words, the field will be presented in a simplified Lexinote-style discussion. Detailed alphabetical indices in English and French, the two international languages of the area, will facilitate the location of a specific item: one can either look up a 
word of particular interest in itself, or look for something in the semantic area required, as an entrée to the whole field.

\section{Conclusion}

The use of wordlist collection as a sampling technique and a basis for comparing languages has a considerable history in West Africa and comparable areas of the world. While we may today be aware of various limitations and problems of the method it is not to be wholly discarded. With thoughtful use it can still yield useful data, and in addition it can feed into more sophisticated studies of genetic relationships and comparative lexicology. This, in turn, will lead to better comparative lexicography.

\section{Notes}

1 My apologies to Clarence Barnhart who used the term 'Lexinote' before me. I graciously accept the (as yet un-offered) apologies of Reinhard Hartmann who started using the word after me. It is obviously a term whose time has come.

Detailed acknowledgements for data take up a whole page: blanket thanks to colleagues in GILLBT and the University of Ghana, officers of Governmental and non-governmental agencies in the various locations, chiefs, elders and many individuals in the language communities. Also to Clara Rosingh for keyboarding assistance.

2 One proposed etymology of "barbarian".

3 The only important exception known to me is that of the Mesopotamian cultures which developed some wordlists comparing the Sumerian, Akkadian and Westem Semitic (e.g. Ugaritic) languages. Further details on various linguistic traditions are now appearing in Lepschy's 'Storia' (Lepschy (Ed.) 1990).

4 Item numbers in the 'Swadesh-200' list are henceforth merely indicated by a preceding \#.

5 "English" stands here for whatever language is used to present the stimulus item - English, French, Portuguese, Afrikaans, Arabic, Swahili, Hausa or a local lingua franca.

6 In Mampruli the future negative is the most easily elicited unmarked verb form of a verb.

\section{References}

* marks references in the Appendix

Arana, Evangelina and Mauricio Swadesh. 1967. Diccionario analitico del mampruli. Mexico D.F.: Museo de las Culturas.

1

Badjona, M. 1983. Nawdem-Deutsch Wörterbuch (Dialekt von Siou). Saarbrücken: Universität des Saarlandes. 
Bendor-Samuel, John T. 1971. Niger-Congo, Gur. Berry, Jack and Joseph H. Greenberg (Eds.). 1971: 141-178.

Bendor-Samuel, John T. 1989. The Niger-Congo Languages. Lanham, MD: University Press of America.

Bennett, Patrick R. and Jan P. Sterk. 1977. South Central Niger-Congo: a Reclassification. Studies in African Linguistics 8(3): 241-273.

Berlin, Brent and Paul Kay. 1969. Basic Color Terms: their Universality and Evolution. Berkeley: University of California Press.

Berry, Jack and Joseph H. Greenberg. (Eds.). 1971. Linguistics in Sub-Saharan Africa (Current Trends in Linguistics VIl). The Hague / Paris: Mouton.

Binger, L.G. (Capt.). 1892. Du Niger au Golfe de Guinée (2 Vols.). Paris: Hachette.

Blass, Regina. 1975. Sisala-English / English-Sisaala Dictionary. Tamale, N.R.: Ghana Institute of Linguistics (now GILLBT).

Brasseur, Georges and Guy le Moal. 1963. Cartes ethnodémographiques de l'Afrique occidentale, feuilles $3 / 4$ nord. Dakar: IFAN.

Busane, Masidake. 1990. Lexicography in Central Africa: the User Perspective. Hartmann, R.R.K. (Ed.). 1990: 19-35.

Christaller, J.G. 1875. A Grammar of the Asante and Fante Language Called Tshi (Chwee, Twi). Basel: Basel Evangelical Missionary Society.

Christaller, J.G. 1889. Sprachproben aus dem Sudan von 40 bis 60 Sprachen und Mundarten hinter der Gold- und Sklavenküste. Z.A.S. 3: 133-154.

Dakubu, Mary Esther Kropp (Ed.). 1977. West African Language Data Sheets I. no place: WALS.

Dakubu, Mary Esther Kropp (Ed.). 1980. West African Language Data Sheets 11. Leiden: WALS / African Studies Center.

Delafosse, Maurice. 1904. Vocabulaires comparatifs de plus de 60 langues et dialectes parlés à la Côte d'Izoire et dans les régions limitrophes. Paris: Leroux.

Delord, J. 1968. Le kaure de la Polyglotta Africana et le kabré d'aujourd'hui. African Language Review 7: 114-139.

Derman, Tankar. 1983. Dictionnaire tem-frangais-allemand / Tem-Französisch-Deutsch Wörterbuch. Saarbrücken: Universität des Saarlandes.

Durand, J.B. (Fr.). 1953. Dagaari-English Dictionary. Jirapa: Catholic Mission.

Fivaz, Derek and Patricia F. Scott. 1977. African Languages: a Genetic and Decimalized Classification for Bibliographies and General Reference. Boston, Mass.: G.K. Hall.

Fortes, Meyer. 1949. The Web of Kinship among the Tallensi. London: OUP.

Goldsmith, John. 1992. A Note on the Genealogy of Research Traditions in Modern Phonology. Journal of Linguisties 28(1): 149-163.

Greenberg, Joseph H. 1966/70. The Languages of Africa. Bloomington, Indiana: Indiana University. (IJAL 29(1) 11. The Hague: Mouton.)

Groh, B. 1911. Sprachproben aus zwölf Sprachen des Togo-Hinterlands. MSOS 14: 227-239.

Hair, P.E.H. 1965. Temne and African Language Classification before 1864. Journal of African Languages 4: 46-56.

Hair, P.E.H. 1966. Collections of Vocabularies of Western Africa before the Polyglotta. Journal of African Languages 5: 208-217. 
Hair, P.E.H. 1968. An Ethnolinguistic Inventory of the Lower Guinea Coast before 1700. African Language Review 7: 47-73.

Hall, Edward. 1983. Ghanaian Language: with Fold-out Map. Accra: Asempa.

*Hall, John F. S.a. (1948). Dictionary and Practical Notes, Mossi-English Languages. Ouagadougou: Mission des Assemblées de Dieu.

Hansford, Keir, John T. Bendor-Samuel and Ron Stanford. 1976. Index of Nigerian Languages. Ghana: S.I.L.

Hartmann, R.R.K. (Ed.). 1990. Lexicography in Africa. Exeter Linguistic Studies 15. Exeter: University of Exeter Press.

Huttar, George and Kenneth Gregerson (Eds.). 1986. Pragmatics in Non-Western Perspective. Dallas: S.l.L./University of Texas at Arlington.

Katia Camara, C. 1983. Tagbana-Deutsch Wörterbuch. Saarbrücken: Universität des Saarlandes.

Koelle, Sigismund W. 1854. Polyglotta Africana. London: CMS.

Köhler, Oswin. 1964. Gur Languages in the Polyglotta Africana. African Language Review 3: 65-73.

Kröger, Franz. 1992. Buli-English Dictionary. Münster/Hamburg: Lit.

Langdon, Margaret A. and Mary J. Breeze. s.a. (1981). Konkomba-English/Likaln-Likpakpaln Dictionary. Tamale, N.R.: Ghana Institute of Linguistics (now GILLBT).

Lavergne de Tressan, M. de. 1953. Inventaire linguistique de l'Afrique Occidentale Française, et du Togo. MIFAN No. 30. Dakar: MIFAN.

Lebizaka, Koyenzi Kézié. 1979. Kabiye-Deutsch Wörterbuch. Saarbrücken: Universität des Saarlandes.

Lepschy, G. (Ed.). 1990. Storia della Linguistica I. Bologna: il Mulino.

Manessy, Gabriel. 1975. Les langues OtiNolta. Paris: SELAF.

*Manessy, Gabriel. 1979. Contribution à la classification généalogique des langues voltaïques: - le proto-central. Paris: SELAF.

Meinhof, Carl. 1906. Grundzüge einer vergleichenden Grammatik der Bantusprachen. Berlin: D. Reimer.

Melançon, Lucien and André Prost (R.PP.). 1972. Dictionnaire buli-français. Dakar: Univ. de Dakar.

Mukarovsky, Hans. 1976. A Study of Western Nigritic 11. Wien: Institut für Ägyptologie und Afrikanistik der Universität Wien.

Mukarovsky, Hans. 1977. A Study of Western Nigritic I. Wien: Insthtut für Ägyptologie und Afrikanistik der Universität Wien.

Naden, Tony. 1986a. Première note sur le konni. JWAL XVI(2): 76-112.

Naden, Tony. 1986b. Social Context and Mampruli Greetings. Huttar and Gregerson (Eds.). 1986: 161-199.

Naden, Tony. 1988. Language, History and Legend in Northern Ghana. Sprache und Geschichte in Afrika 9: 205-246.

Naden, Tony. 1989. Gur. J.T.Bendor-Samuel (Ed.). 1989: 141-168.

Prost, André (R.P.). 1966. La langue gurma dans le Polyglotta. Africana. African Language Review 5: 134-138.

Prost, André (R.P.). 1975. Vocabulaires comparés des langues de l'Atakora. BIFAN 37, B (2): 412448.

*Rattray, R.S. (Capt.). 1932. Tribes of the Ashanti Hinterland. (2 Vols.). Oxford: O.U.P. 
Riccitelli, J.M.R. 1955. Pedagogic Grammar - Red Bobo, Ouarkoye Dialect. No place.

Sankoff, David. 1970. On the Rate of Replacement of Word-meaning Relationships. Language 46(3): 564.

Schadeberg, Thilo C. 1986. The Lexicostatistic Base of Bennett \& Sterk's Reclassification of NigerCongo with Particular Reference to the Cohesion of Bantu. SAL 17(1): 67-83.

Spratt, David and Nancy Spratt. s.a. (1975). A Kusaal-English Dictionary. Tamale, N.R.: Ghana Institute of Linguistics (now GILLBT).

Swadesh, Morris. 1950. Salish Internal Relationships. IJAL 16: 157-167.

Swadesh, Morris. 1953. The Languages of the Archaeologic Huastecs. Camegie Institution of Washington, Dept. of Archaeology, Notes on Middle American Archaeology and Ethnology 114: 223227.

Swadesh, Mauricio, Evangelina Arana, John T. Bendor-Samuel and W.A.A. Wilson. 1966. A Preliminary Glottochronology of Gur Languages. Journal of West African Languages III(1): 2765.

Westermann, Diederich. 1935. Nominalklassen in Westafrikanischen Klassensprachen und in Bantusprachen. MSOS 38(3): 1-53.

Westermann, Diederich and Margaret A. Bryan. 1961. Languages of West Africa. Handbook of African Languages. London: OUP for I.A.I.

"Wilson, W.A.A. 1972. Dagbani, an Introductory Course. (2 Vols.). Tamale, N.R.: Ghana Institute of Linguistics (now GILLBT). 
Table: "Come" and "Go"

FORM

"TI

*TA (cf.

"REACH",

"SEND"(iii)

*WE

"YE

*GA (cf.

"PASS")

*KEN
"GO"

MP/SF ti

BL ta (?tua?)

$\mathrm{HG}^{\mathrm{A}} / \mathrm{KR}(\mathrm{N})$ we

$\mathrm{KR}$ (Hunt) waya

$$
\begin{aligned}
& \mathrm{HG}^{\mathrm{B}} \text { gaa/gaari } \\
& \text { KR(P) gaate! } \\
& \text { KR(P,N) gaariya } \\
& \text { DR(K) ga/gere } \\
& \text { DR(E.Hall) gaa } \\
& \text { WL gaa/gara } \\
& \text { BL ga; KM ga/ } \\
& \text { gara/gama!/gana }
\end{aligned}
$$

DB chap/chema/chendi

MP kyappi/kyema!/

$\mathrm{KR}(\mathrm{N}) \mathrm{c} \varepsilon \mathrm{ma}$ !

\section{KLA ken/kenne \\ KLT(N) kiq,cin \\ NB kep/kem!/keenya \\ TL ken,kyapi/ \\ kyema!/kyenya}

FR kip(e)/kene/kena!/kene

NK(N) sena/seni

MR(J,P) kyene

$\mathrm{MR}(\mathrm{H}, \mathrm{N})$ kende

MR(O) kêng/kênda

DR(J) cip; DG kye

LB(R) cep/ceri

NR(J) cen; BR(J) cen

SF(J) cini

BL (ga)/kyeena/chep
"COME"

KLT tin...na

HG ta/tani

$\mathrm{NB}^{\mathrm{A}} / \mathrm{KR} / \mathrm{TL}\left(\mathrm{N}^{\mathrm{A}}\right)$ ta...na

$F^{A}$ wa'an...na,

wa'ana/wa'ane...na

MR wa/watwaoongo

$\mathrm{DR} / \mathrm{BR} / \mathrm{LB} / \mathrm{NR} / \mathrm{SF}$ wa

WL wa/waana; NT waare

FR $^{\mathrm{B}}$ ye'a...na/ye...na

DB ka/kani/kama!/kandi,...na

MP kye/kyem/kyenni,...na

HG chena ("be coming")

KLA kep...na

KL(R) kyem

$\mathrm{NB}^{\mathrm{B}}$ ki...na,(R) kyim

TL(J) kyevo...na

TL(R) kyim

TL(A) kam...na

TL $\left(N^{B}\right)$ kyem...na

$\mathrm{FR}^{\mathrm{C}}$ kena...na
BL(P)ja/jam!/jaya

BL(Gray) chee...na

KM ken...ge

keenini/kenye 
"WALK"
"BE GOING"

MP ti

FR/MP/WL ta

HG/KR(N) wara

MP wa/wara

KLA wa'e/wa'ana

KLT We'e

FR ye'/ye'a

NB ye'e

TL yeaa/yaa

DR gere

${ }^{*} \mathrm{GA}$

$\mathrm{KR}(\mathrm{P})$ gaate

WL gara(la)

'TI

*TA

*WE

*YE
FORM

*KEN

DB as "go"

MP as "go"

HG chanoil

chapina

KL as "go"

$\mathrm{NB}(\mathrm{N}) \mathrm{ken}$

$\mathrm{NB}(\mathrm{R}) \mathrm{kim}$

FR as "go"

MR as "go"

NT cangi/cangto

DR cep/cene/cepe

LB cene

WL chep/chene

$B R$ cin; SF cio

BL cep,cen

KM chuo/chuma/

cumma! 
Appendix. Western Oti-Volta Lexinote No. 3.

\section{Coming and Going.}

In English idiom, complete confusion is in the state of one who 'doesn't know whether he is coming or going'. We might well imagine that a similar fate might overtake one who held the Rattray (1932) theory that the languages of Northern Ghana, or at least 'Mole-Dagbane', are interchangeable dialects of a single language.

1. A quick glance at survey-type samples of vocabulary from the major or more-accessible languages of the group might suggest to the person envisaged above the simple generalization that all the languages have a verb which one might summarize as " $K E(N)$, where the first consonant ranges from [k] via [ky] and $[t]]$ to $\left[t^{h}\right]$, and the vowel from [æ] through $[\varepsilon]$ to [1], and which means "go, walk" and, with the addition of a final na, "come". Thus we have ka in DB 1 (kana "came") ken in KLA, kyenni MP ("walking", kyena "came"), cen in $\mathrm{NR} / \mathrm{BR}(\mathrm{J})$, tin in KLT, and ta in HG.

The above is fine until you ask, e.g. in MP, for:

and get:

$$
\text { "where are you going?" - "I am going to market." }
$$

Ya ni ka i wa? - N wa la daa.

(where to that you going - I going (assert.) market)

(alongside Kyema! - "Go!" and Kyem na! - "Come!"). It transpires that in a number of these languages "going" in the present ("continuous' or 'progressive') must·be realized by a different root from that used in the past, future, imperative and infinitive (in some other $\mathrm{O} / \mathrm{V}$ languages, for instance Kokomba and Nawdm, the same occurs with "come", thus giving four distinct roots "go", "be going", "come", "be coming"). The basic verb means both "go" and "walk" but in the present it is unambiguously "walking" - cf. MP U kyenni ni. "He is walking." (usually heard in reference to a child's stage of development - i.e. habitual imperfective rather than progressive), while perfective U kyappiya. can mean "He went." or "He walked." (to emphasise the latter, add "(his) feet." - Lexinote \#12 forthcoming).

Then after some years in Mampruli I heard $\mathrm{N}$ ti la ... for "I went to ..." and I ti la ya ni? "Where did you go/are you going?", showing that in at least one language the *TI root is used alongside the *KEN, proving them to be distinct. Several languages also have $t i$ and/or ta as a particle or auxiliary indicating purpose/intention/achievement and/or change of scene between verbs in a series (cf. Wilson 1972 II. Ch. 50).

Further research in the group throws up at least three other roots *TA, " $G A$ and "WE; this last one would expect to be the origin of both the MP wa 
above and the FR ye' by the semivowel-harmonizing tendency noted in Lexinote \#3, ("sun" "WEN $\rightarrow$ wun, yen), but FR has both ye' "going" and wa'(an(na)) for "come" so for the moment we will keep wV and yV separate. These various roots mix ' $n$ ' match in a complex way in the various languages; the vocabulary for "come" and "go" (cf. Table) attempts to set this out in two dimensions.

2. There are also a number of verbs of motion with more specific content "go in", etc. - which I usually gloss with a single word ("enter","exit") where possible to avoid congestion in the "go" section of the dictionary. We may define these verbs of motion as those which take the complement of destination (or, for "exit", of origin - etc.) without an intervening "go" verb, in contrast with verbs of manner of locomotion such as "run" - you can say "entered (into) the room" but not "ran to the room" which would have to be "ran, went to the room": this distinction is clearly set out in Wilson (1972 II, Ch. 21). The "hither" particle of the "come" verb (not in HG or the North-western group) can also be used with these words to contrast "come in" with "go in" (within "enter"), and so on. This is obligatory if the motion is towards the speaker, so that if you are speaking of someone falling from a tree, for instance, you have to say "He fell hither." - i.e. coming to the ground where the speaker is located. In fact the verb need not be one of motion: one can speak of "buying something hither" meaning to go somewhere and buy it and bring it here. A common way of saying "Bring it!" or "Hand it over!" is (as is just possible in English) 'Have it here!' - in MP Mari ka na!, FR Tare ka na!.

As in many languages the axis by which the 'hither' is determined is the speaker's present location, or his location at the time (past or future) of the motion concerned, or his normal or expected location; the scope of 'location' depends on the distance of travel - someone from outside the village "comes" to Gbeduuri (any part thereof), while someone from the village only "comes" to my house (or where I am, or was, or will be...). If anything, the use of na is even broader than Eng. "come"; in a narrative it is often used if the next event takes place where the motion arrived at.

A further dimension is added by the possibility of making a causative derivative: "go in" $\rightarrow$ "put in": in MP, at least, this is almost certainly a productive process, suffix -si. The same is found sporadically (possibly universally, the sporadic nature belonging to our sources of data) in most of these languages - forms marked * in the lists below.

Note: In these languages there is a variation $\mathrm{s} / \mathrm{h}$ with various conditions. In DB $h$ is obligatory following a short vowel, in MP before a consonant; in FR and its neighbours *s before a front vowel is $h$. In most of the languages any non-initial $s$ can come out as $h$ in fast or informal speech. It should also be noted that $h$ often nasalizes adjacent vowels - the effect is particular clear in DB \& FR. 
"ASCEND"1, 2 DB du, duhi*; HG du/duura; MP du/duuri, duusi*; KLA du/dut; KLT dos; NB(R) do; TL(R) do, (A) du; $\mathrm{FR}^{\wedge}$ doe/doora; $\mathrm{MR}^{\wedge}(\mathrm{R}) \mathrm{du},(\mathrm{H})$ dou; $\mathrm{DR}^{\wedge} \mathrm{du}$, do/duoro; $\mathrm{LB}(\mathrm{R})^{A}$ do; WL do/duoro, duoho*; $\mathrm{FR}^{\mathrm{B}}$ zom/zona; $\mathrm{MR}^{\mathrm{B}}(\mathrm{R})$ zom; $\mathrm{DR}^{\mathrm{B}}(\mathrm{R}) \mathrm{zom}$; $\mathrm{LB}(\mathrm{R})^{\mathrm{B}}$ zom; $B L(P)$ gyeule, (R) dyur, (Kröger) jue; KM juali (in the Northwestern group the * ZOM items are probably the preferred equivalent for "ascend")

"DESCEND" DB sigi, sigsi*; HG sigi/sigira; MP sigi/sigri, sigsi*;

$\mathrm{KR}$-/sigsiri/sigsiy a*; KL sig, sie*, sigis*;

$N B(R)$ sige; TL(F) sig, (R) sige, (A) sik;

FR sige/sigire, sigera, sigehe, sirehe sigi, siki*;

DR sigi; LB sige; WL sigi, sigihi*;

$B L(R)$ sig, (P) sini; KM sup

"ENTER" DB kpe, kpehi*; HG kpe/kpeera; MP kpe/kpeeri, kpeesi*;

KLA kpen', kpen'es*; TL/NB(R) kpen; TL (A,F) kpe;

FR ken'/ken'enra, ken'enhe*; NK(R) kye; LB kpe;

MR kẽ, kẽẽs*, (R) kye, (H) ke, kese*;

DR kye(n), kpe(n); NT kwen/kwiyento/kwenys;

WL kpe/kpiera; $B L(R)$ dyo, (P) gyo; KM dzu

"EXIT" DB yi, yihi*; HG yi/yiira; KR yi; MP yi/yiiri, yiisi* ("take out, choose"); KL yi, yiis*; NB(R) yim (?imperat.?);

TL yi; FR ye, yehe/yehera, -/yehere*;

MR yi(i)/yit(a), yiimi, (R) yi, (H) woude, yi, yiis *;

NT yi/yito/yiro; DR yi/yie; LB(R) yi;

HG nyisi ("choose"); BL nyin; KM nyin/nyimma!/nyinna

3. All the languages have a verb for "to go home". This is common, amongst other usages, as a farewell spoken by a parting guest: 'I have gone home.' (proleptic perfective - "I am just about to go home."). It, and/or its causative, may be used for "to marry", especially with the woman as subject (the man often 'eats' his wife) and /or "give in marriage".

"GO HOME" DB kuli, kulsi*; HG kuli/kunna, kulisi ("marry"); KR kuli; MP kuli/kunni/kulima!, kulsi* (and "marry"); KL kul; TL kuli, kulh*3; FR kule/kula; NK(N) kuli; MR kouli, kwili, kuili, kuilis* (also "marry"); DR kule; KM kuli/kulimi/kuliya; BL kuli 
4. The separate lexeme glossed "return" then means to go back somewhere other than home (or in the collocation 'return, go-home' - "to go back home"), or to go backwards (specifically 'return his (etc.) back'), or to do (something) again. The causative, besides "take/send back", often also means "to answer" a question.

"RETURN"

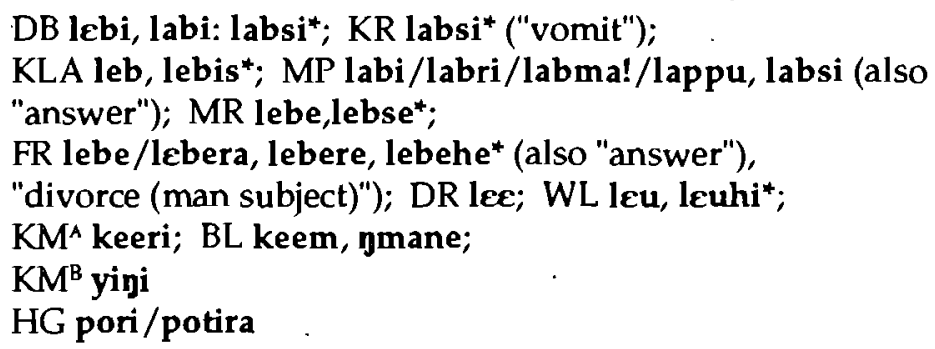

5. We have noted above that some verbs, 'means of locomotion' like "run", "jump", need one of the 'verbs of motion' discussed in this note to indicate the goal or origin of motion ("jumped in" = "jumped, entered"; "ran to town" = 'ran, went town'). Even the verbs of motion, however, do not assert the attainment of the goal. There is yet another lexeme which signifies arrival, and to show that the runner actually reached town one may need to say 'ran, went, reached town'. This verb, glossed "reach, arrive" is in most of these languages something like the MP paai (MR and DR alone, not here supported by .FR or KL, have a reflex of the *TA which Manessy (1979) sets up as a 'common central Voltaic' proto-form - V.C.1; see also the "TA forms in the Table). This is the

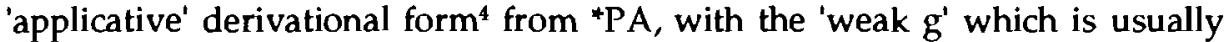
lost in the vowel, but may surface - especially in DB (Wilson, 1972 II, 6.2) before a vowel-initial pronoun (DB paag'o "reach him" from paai). MP has the base verb pa - "to be immediately on top, to be an immediate successor (e.g. specifically come second in a race, or be the 'next-born' in a family)", derivative paai which not only means "to arrive at the goal of motion" but also "to arrive" of a particular time and "to reach, be enough" in quantity, and further the causative paasi both for the first sense of paai - farewell greeting Naawunni paasi ya.! - "God will cause you to arrive (sc. safely)!" - and in the last sense - "cause to reach/be sufficient", this being the normal term for "add"; this m-paasi (serial infinitive 'to add') is often found after other verbs in a series with the quasi-adverbial meaning of "additionally". Whether paali "fill" and paam "plait" are also derived from the same base is less decidable.

\footnotetext{
"REACH, arrive" DB paai (paag')/paama/paabu, pahi*; HG paa (paag');

KR paa;

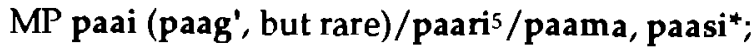

KLT paa; KLA paae/paad, paas*; NB(R) pa;

TL paa, pa'a (N), paa (F, R); FR pae/paare;
} 
MR ta, tall, tase*; DR ta; $L B(R)$ ta;

[WL pa(g-) "meet"]; BL pae (R)/paare/paaya (P);

KM tugi

6. "To cross" is less commonly represented in the sources, and the vocabulary below may represent several distinct lexemes: the *YAK items, for instance, may be specifically to cross over the top of (cf. the common MP collocation yikki n-yakki - "jump/fly over"), while "LO(N) may perhaps be "pass through" (? cf. MP longu "throat" which is also "interior cavity").

"CROSS" DB yagi; MPA yakki; FR yake/yakere; (HGA yagi "come of") $\mathrm{HG}^{\mathrm{B}}$ loo; $\mathrm{MP}^{\mathrm{B}}$ looi, lokki, longi; KL lo'on; DB looi; MR^ $\operatorname{loog}($ "go past");

$F^{B}$ doe (cf. "ascent"); $M^{B}$ doage; DB duui (duli*); $M^{c}$ piouge, piuug; MR budga; $B L$ tam; H' ${ }^{c}$ pulli

7. Most of the languages have a verb, or perhaps two verbs, "to surround" and "go round". "Surround" may be positional ("we are surrounded by the enemy") or motional ("send a task force to surround that town"), while "go round" may imply a circumnavigation ("he went right round the house and came back to us at the gateway") or a detour ("there was a puddle on the path so I went round it"). The sources are not usually clear enough to attribute these various senses to the respective items. In MP n-gyili is "to go round" (including "to wander around aimlessly" - see 9 below) and n-gyiligi "to surround" (Na Gyerimja built a wall n-gyiligi Nalerigu "around Nalerigu (town)").

"ROUND"(go -, be -) DB, WL gili; MP gyili/gyinni, gyilgi;

HG jili, giligi; KL gilig; FR ${ }^{A}$ gilige /giligera;

MR` gilige; DR gol;

BL kia, kiage; $M R^{B}$ kae/kaara;

$M R^{c}$ saaga, gubig, gubga (+adv. gilli)

Wordlists more often have adjective or adverb "round" which is "GIL (/GBIL/KPIL/KIL...) in DR, BL, HG, FR, KL, KR, KM, MP, MR, NB, SF, TL.

8. Our next verb is "to pass", which may mean to go past a fixed spot, or to overtake someone travelling on the same route as oneself. It is also used, in MP at least, for "Come/Go on!" - urging a child or companion not to dawdle, or someone not to hang about but to continue on their journey. This verb also (? from the "overtake" sense ?) means "to surpass" and is used in comparisons; the most obvious form is where it follows a descriptive verb: 
U veela n-gaari i. "She is prettier than you."

(he/she is pretty to-pass thee)

"PASS"

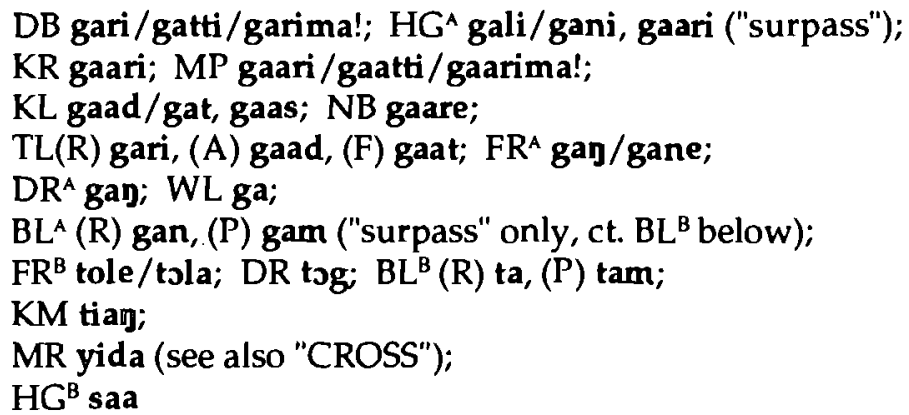

Note: The majority of forms are derived by various thematic consonants (l, $n, r,-$ all frequent in this function) from a base ${ }^{*} G A$ which we may reasonably identify with the item in the Table. Do BL, ?KM, ??FR, DR derive similarly from *TA therein? The KR forms in the table imply gaar- for "go" there.

9. These languages also have a verb meaning "to travel, journey, roam, wander". As this gloss suggests, this can be used for just "going for a walk" ("I don't have any business, I'm just roaming." - cf. on MP "go round", 7 above). It can also mean to take a specific journey: the MP welcome is $\mathrm{Ni}$ i goorim ! "with your travelling" (Naden 1986b). The verb can also indicate travelling in general, the same MP greeting being appropriate to greet someone passing (e.g. on a bicycle) whose start and end points and destination are unknown. A welcome may include a greeting for the goorim-dima - "the people you met on your travels".

"TRAVEL" DB go/gori/goya, (n.) gorim; HG go/goora; KR go; $\mathrm{MP}$ go/goori/goya, (n.) goorim; KLA^ guann/goon;

TL goma (F, ? impat.?); $\mathrm{MR}^{A}$ go,gõ(od);

$\mathrm{KLA}^{\mathrm{B}}$ eed; FR eere/cera; $\mathrm{MR}^{\mathrm{B}}$ yeebe; $\mathrm{KM}$ (n.) diisi;

BL $(G, P)$ nyeem,(N.,D) cerim

10. In section 1., on basic "go, come", we did not discuss causative derivatives. In fact morphological derivatives of these bases do not seem to be found except for the link with "pass" (note to vocabulary in 8 above, "GA, TA) and with "send" (below "SEND" iii, "TA). There are separate lexemes for "send"; in fact local English has a number of different 'send's:

a) Two of these are "to send, or 'message"', the contrast between the two being that although in both cases the Agent, the sender, entrusts an errand or mes- 
sage to the person sent, in one case he is "sending" someone who otherwise would have no reason to go, while in the other he entrusts his errand to someone who is going anyway on his own business:

i) "SEND (on an errand)" DB tim; HG tumi/tumina; KL tum; BL tom; MP tum/tumni / tumma! / tumpu; FR tom /tone; MR toum, tum ${ }^{6}$

ii) "SEND (message with sb.)" HG tolimi; MP tolim; MR tole; KLA tolisi;

b) In local Eng. "send" is also used for the situation where the Agent actually transports or travels with the person 'sent': "I had to go to Nalerigu in my lorry to send the Chief to Hospital." The only sure examples I have of this are derivatives of the *TA base of "go".

iii) "'SEND' (take sb. to..)" DB tahi; HG/MP taasi; TL ta'ah; MR tall; (? BL ta);

c) There are two further verbs involving two people travelling together. One is usually translated "follow", but basically means rather 'to accompany in a subordinate or secondary position'. Thus we have the local English "If you are going to Tamale in your lorry, may I follow you?" meaning "Will you give me a lift?" not "May I drive along behind?". This is therefore rather "be a follower of"; to get the usual meaning of the Eng. "follow sb." you have to say "follow sb.'s back'. There are also collocations of "follow" with a path or placename in the sense of "go via ...". The other sort of 'accompanying' implies that the 'follower' is the more important - "lead" is sometimes used in local Eng. - and it is particularly used in "Take me to your leader!" Type situations: the subject of the verb "escorts" someone to show him the way, introduce him to the person to be visited, or just to provide a guard of honour to add dignity to his progress.

i) "ACCOMPANY, 'follow'" DB doli/dola/dola!; MP doli/dola/dola!;

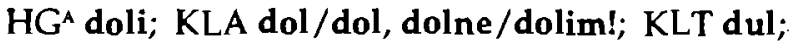

TLA (F) doli; FR^ dole/dsla; TL ${ }^{B}$ duh (vocab. 3, note);

FR $^{B}$ doohe;

$M R^{A}$ toun,tũn, tuu,tule; $\mathrm{MR}^{\mathrm{B}}$ pogele,pugla;

DR beere (cf./ct. ii) below);

BL sape; $K M^{A}$ supun; $K M^{B 2}$ dii/diiya;

$H G^{B}$ pa...zu (normal way of expressing this sense; cf. "REACH")

(zu is "head, on") 
ii)

"ESCORT,'lead" " DB bicli; HG beeli/beena; KLAA biel;

MP beeli/beenni/beelima!; FR beele; DR biel, beele;

TL^ beeh; BL bane;

$\mathrm{MP}^{\mathrm{B}} \mathrm{kJ}$ 'ali ("give a lift on bike, horse");

$\mathrm{TL}^{\mathrm{B}}(\mathrm{F})$ kogal;

$\mathrm{KLA}^{B}$ pi'e; MR nyage; KM supun (see i) above, q.v.

11. Our final verb of motion is "to be near" which itself or in a derivative may also be "to get near, approach". In MP there is a syntactic distinction between the predication types, the process ("come near") has the possibility of occurring in the imperfective with the verb-assertive particle ni: U potti ni. - "He is approaching." - or in the absolutive (verb is final in the clause) perfect with ya: U poriya. - "He has approached." (these are the normal active verb frames). The stative frame appropriate to "be near" allows the verb stem followed by both the perfective and the assertive markers (this is impossible for action verbs): U poriya ni - "He is near."

"NEAR" (be -, get -) ( is "get near, approach")

$\mathrm{DB}(\mathrm{R})$ miri, (Okraku Dict.) mire, (N) muri, (O) miri /mirti

$\mathrm{MP}^{\wedge}$ miri/mitti (rare);

$\mathrm{MP}^{\mathrm{B}}$ pori/potti/porima! ( ${ }^{*}$ also); KLA ${ }^{\mathrm{A}}$ ponri;

$\mathrm{NB}(\mathrm{R})$ pore; $\mathrm{TL}(\mathrm{N})$ pori, $(\mathrm{F}, \mathrm{A})$ poriga (?*); $\mathrm{FR}^{\wedge}$ ponre;

$\mathrm{NK}(\mathrm{R})^{\wedge}$ pore; $\mathrm{MR}^{\wedge}$ peya; SF peel; $\mathrm{WL}^{\wedge}$ pieli;

$\mathrm{NK}(\mathrm{R})^{\mathrm{B}} / \mathrm{MR}^{\mathrm{B}}$ kolege; KLA ${ }^{B} \mathrm{kpi}^{\mathrm{i} e} / \mathrm{kpi}^{\prime} \mathrm{ene} ; \mathrm{DR}{ }^{*} \mathrm{kpiele}$;

$\mathrm{BL} *$ kpaje;

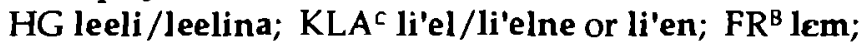

$\mathrm{BL}^{\mathrm{A}}$ gela; KM gbagi;

$\mathrm{BL}^{\mathrm{B}}$ mosta (caus. mostte "bring sth. near");

WL ${ }^{B}$ tohi

The inverse "be far" does not, to my knowledge, have a "go far, s'éloigner" sense in any of these languages". "Be far" is usually a descriptive verb "be long, tall, far", basic form *WOG, with various adjectival and adverbial derivatives.

\section{Notes to Appendix}

1 The Western (and other) Oti/Volta languages are referred to here by the standard two-letter codes (Swadesh et al. 1966, Naden 1989):

$\begin{array}{lll}\text { BL } & - & \text { Buli (O/V Buli) } \\ \text { BR } & - & \text { Birifor } \\ \text { DB } & - & \text { Dagbani } \\ \text { DG } & - & \text { Dagara (B. Faso) } \\ \text { DR } & - & \text { Dagaari }\end{array}$

$\begin{array}{lll}\text { KM } & - \text { Konni (O/V Buli) } \\ \text { KR } & - \text { KaMara } \\ \text { LB } & - & \text { Lobiri' }\left(R^{2}\right) \\ M P & - & \text { Mampruli } \\ \text { MR } & - & \text { Moore }\end{array}$




\begin{tabular}{|c|c|c|c|c|}
\hline FR & - Frafra & NB & - & Nabit \\
\hline$G N$ & Gurenne $\left(J^{2}\right)$ & NR & - & Nura \\
\hline HG & Hanga & NT & - & Nootre \\
\hline KL & Kusaal & SF & & Safalaba \\
\hline KLA & Kusaal Agole (West) & $\pi$ & & Talni \\
\hline KLT & Kusaal Toonde (East) & WL & - & Wali \\
\hline
\end{tabular}

2 Other abbreviations:

/ - separates paradigan co-forms singular/plural (Noun), neutral/imperfective/ imperative/verbal noun (Verb)

A,B - (partial) synonyms or different sources for the same language

(A) - written data from Abraham Manga (TL)

(F) - data from J. Hall (1948) (MR)

(H) - data from Fortes (1949 and other writings) (TL)

(J) - data from JWAL article - Swadesh et al. 1966

(K) - data from J. Kennedy (DR)

(N) - data from Tony Naden field research

(O) - orthographic form from published material

(P) - data from Prost (various publications, N.B. Melançon and Prost 1972 (BL))

(R) - data from Rattray (1932)

$3 \quad$ TL distinguishes reflexes of *-Sl and *-FU as a final -h with spread and rounded lips respectively

4 cf. MP te "spread (self)" - teaai "straighten, stretch out sth."

$2 \varepsilon$ "blow (wind)" - zeaai "blow something (away)"

This structural type of derivative may also be inversive in sense:

ye "put on (shirt, etc.)" - yeaai "take off (...)"

yo "open" - yoaai "close"

and singulative:

gba "catch" - gbaai "catch (one only)"

5 Far-west dialect imperfective paagri.

$6 \pi$ (F) tumh (" causative, see note in 2 above) "follow through kinship links".

7 MR does have zãa "être loin" vs. zãage "éloigner" (move something to a distance); cf. FR zaam "be deep". 